\title{
RANDOM MACHINE BREAKDOWN AND STOCHASTIC CORRECTIVE MAINTENANCE PERIOD ON AN ECONOMIC PRODUCTION INVENTORY MODEL WITH BUFFER MACHINE AND SAFE PERIOD
}

\author{
Brojeswar PaL ${ }^{1}$ AND Subhankar Adhikari ${ }^{2, *}$
}

\begin{abstract}
In this paper, we have developed an economic production quantity (EPQ) model in which production is executed mainly by the original machine. But when the system faces disruption, the buffer of it continues the production. Here, we incorporate a fixed Safe Period running policy, in which the machine runs interruptedly, whenever production commences. The disruption of the system may occur at any moment of the time horizon over the safe period, and then, it will go under the corrective maintenance policy. Here, we take that both of the time of disruption and period of maintenance are continuous random variables. We have discussed the model under different safe period duration with corresponding disruption situations. Our main objective is to minimize the expected average total cost for all the cases concerning the production lot size. The model has also been illustrated numerically with some examples. To examine the robustness of the solution of this model, we discuss the sensitivity analysis for the parameters.
\end{abstract}

Mathematics Subject Classification. 90B06.

Received December 7, 2019. Accepted June 23, 2020.

\section{INTRODUCTION}

The machine is inevitable in a production system. Since the smooth running of it during the production period is not a reliable incident, we can state that there is a close relationship between the production system and its disruption. From a manufacturer's point of view, disruption is not a desirable thing. So it is expected that the manufacturer should use a reliable machine such that there are some recovery policies during the machine disruption situation. "Safe Period" is one of those policies in which the system can run interrupted. For example, the sewing machine making brand Singer provides such a period in which the chance of breakdown is negligible. The garment industry is depended heavily on the sewing machine. It is evident that if offered "Safe Period" falls within the production time, then there will be chances of disruption. Then corrective maintenance is implied to bring the machine in working condition. The length of the maintenance period is quite unpredictable, as it depends on the intensity of the breakdown. If corrective maintenance's period is too long, the manufacturer may experience shortages of inventory, which hampers the goodwill/reputation of the business. Due to highly

Keywords. Inventory, breakdown, maintenance, buffer machine, safe period.

1 Department of Mathematics, The University of Burdwan, Burdwan 713104, India.

2 Department of Mathematics, Chandernagore College, Chandernagore 712136, India.

*Corresponding author: subhankar_adhikari@yahoo.com 
competitive market situations, people have many options to fulfill their demands from different sources. So during the stock-out period, the amount of lost sales has a significant contribution to increasing the average total cost of the system. To overcome these sorts of problems, the company may implement the concept of a buffer machine. It will run throughout the corrective maintenance period as a substituted one. It is quite reasonable that the production cost of an item by the buffer machine is higher than that of the original machine. Therefore, the manufacturer has to bear an extra cost for hiring the machine. But drop-out of customers during the stock-out situation can be avoided to maintain the goodwill of the business, which is one of the most crucial criteria in the present market scenario.

Now our following discussion consists of different previous research works in the machine breakdown environment accompanying various repair periods and maintenance policies.

\section{LiterATURE SURVEY}

In a production system, failure and maintenance of a system are the most important things. Chelbi and AitKadi [4] formulated a production inventory model considering random failures along with the determination of periodic preventive maintenance period and buffer stock level. Giri and Dohi [10] studied a production inventory model, where they assumed that both the machine breakdown and corrective repair time are random, and the production rate is a decision variable. Later, Darwish and Ben-Daya [8] developed a two-stage imperfect production-inventory model (PIM) considering the effect of inspection error and the preventive maintenance policy. Kenne et al. [13] described an inventory model where production planning was dependent on the age of the unreliable machine. After that, two types of inspection policies under the machine breakdown situation were considered by Giri et al. [3]. Boschian et al. [2] studied a simulation model consisting of two machines acting simultaneously in a random failure situation. A Markov decision model for the deteriorating system was developed by Karamatsoukis and Kyriakidis [12]. Chiu [6] formulated an imperfect PIM with a random machine breakdown taking failure in the period of reworking for the defective items. Nourelfath [16] developed a multiproduct, multi-period PIM, together with random machine failure taking random production rate and customer service level. Sana [20] considered an imperfect production system with costless repairing warranty, where he incorporated the concept of buffer inventory level during preventive maintenance. A PIM, where preventive maintenance was non-cyclical, was studied by Fitouhi and Nourelfath [9]. Chiu [6] developed a production planning problem where the number of machine breakdown per unit time was a discrete random variable that follows a Poisson distribution. A significant review paper was written by Horenbeek [11], mainly keeping in mind the effect of different maintenance policies on the inventory system. Wee and Widyadana [24] considered that the unavailable time of the production was a random variable that follows uniform or exponential distribution. A discontinuous multi-delivery policy with the failure-prone machine was studied by Chiu et al. [7] in an integrated economic manufacturing quantity model. Rafiei et al. [19] studied a production-inventory system consisting of two parallel machines where both demand and lead time were random variables. Luong and Karim [15] developed an integrated PIM for deteriorating items considering both times to machine breakdown and repair as random variables that follow an exponential distribution. Kim and Glock [14] discussed the functioning of multiple parallel machines with variable production rates in a two-stage problem. Taleizadeh et al. [23] considered a discrete shipment in a vendor and buyer integrated model under a defective production system with a random breakdown of machines. Peymankar et al. [18] showed that in a machine breakdown situation, the external supplier was a better option for the manufacturer. They also studied three types of incidents under machine failure situations: emergency replenishment, revenue-sharing contract, and price discount contract. Besides, Pal et al. [17], Shi [21], Taleizadeh et al. [22], Cheng et al. [5], Bahria et al. [1], etc. studied different models in this direction.

The novelty of our proposed work compared to the existing pieces of literature has been discussed in the following Table 1.

Here, the following assumptions are taken up to develop the model. 
TABLE 1. Comparison of the work with the existing paper.

\begin{tabular}{|c|c|c|c|c|c|}
\hline Author(s) & $\begin{array}{l}\text { No of } \\
\text { random } \\
\text { variables } \\
\text { used }\end{array}$ & $\begin{array}{l}\text { Maintenance policy: } \\
\text { preventive } \\
\text { maintenance }(\mathrm{PM}), \\
\text { corrective } \\
\text { maintenance }(\mathrm{CM})\end{array}$ & $\begin{array}{l}\text { Stochastic } \\
\text { maintenance } \\
\text { period }\end{array}$ & $\begin{array}{l}\text { Safe period } \\
\text { strategy whenever } \\
\text { production } \\
\text { commences has } \\
\text { been taken into } \\
\text { consideration }\end{array}$ & $\begin{array}{l}\text { Use of buffer } \\
\text { machine during } \\
\text { the maintenance of } \\
\text { original machine }\end{array}$ \\
\hline Chelbi and Ait-Kadi [4] & Two & Both & Yes & No & No \\
\hline Giri and Dohi $[10]$ & Two & $\mathrm{CM}$ & Yes & No & No \\
\hline Chakraborty et al. [3] & Three & Both & Yes & No & No \\
\hline Chiu $[6]$ & One & $\mathrm{CM}$ & No & No & No \\
\hline Nourelfath [16] & Two & $\mathrm{CM}$ & Yes & No & No \\
\hline Pal et al. [17] & Three & $\mathrm{CM}$ & Yes & No & No \\
\hline Chiu et al. [7] & One & $\mathrm{CM}$ & No & No & No \\
\hline Luong and & Two & $\mathrm{CM}$ & Yes & No & No \\
\hline \multicolumn{6}{|l|}{ Karim [15] } \\
\hline Peymankar et al. [18] & Two & $\mathrm{CM}$ & Yes & No & No \\
\hline Our work & Four & $\mathrm{CM}$ & Yes & Yes & Yes \\
\hline
\end{tabular}

\section{Assumptions}

(1) A single-stage inventory model is considered with an infinite time horizon.

(2) Two machines are involved in the production system. One is termed as the original machine and another is buffered. Both machines have the same rate of production.

(3) Original machine starts the production. When this machine is disrupted, it will be brought under corrective maintenance and that time the production will be carried on by buffer machine.

(4) Disruption of buffer machine is not allowed.

(5) The concept of "Safe Period" is taken into consideration for the original machine. After "Safe Period", disruption of the original machine may take place at any time.

(6) Corrective maintenance periods are considered as a random variable with finite range.

(7) The production cost of a unit by buffer machine is more than that of the original machine.

(8) The cost of hire of buffer machine is included in the setup cost. This cost has to be bearded even if a buffer machine is not used for a single time within the inventory cycle.

(9) Shortages are not possible as buffer machine works always during the corrective maintenance period of the original machine.

\section{Notations}

The following notations are used throughout the paper.

$P \quad$ Rate of production.

$R \quad$ Rate of demand.

$\alpha \quad$ Safe Period.

$\tau_{1} \quad$ Random variable which denotes the time when first disruption occurs.

$\delta_{1} \quad$ Random variable which represents the length of the first corrective maintenance period.

$\tau_{2}$ Random variable which denotes the time period starts from the end of first corrective maintenance up to second disruption.

$\delta_{2} \quad$ Random variable which represents the length of the second corrective maintenance period.

$M_{1} \quad$ Upper bound of the first corrective maintenance period.

$N_{1} \quad$ Upper bound of the second corrective maintenance period. 
$t_{\mathrm{p}} \quad$ Total production time.

$h \quad$ Holding cost per unit item.

$k \quad$ Set-up cost.

$T \quad$ Length of the inventory cycle.

$Q \quad$ Ordering lot-size.

$C_{\mathrm{m}} \quad$ Cost for the corrective maintenance per unit time.

$C_{1} \quad$ Cost per unit item produced by the original machine.

$C_{2} \quad$ Cost per unit item produced by the buffer machine.

$I_{1} \quad$ Inventory level during production time.

$I_{2} \quad$ Inventory level when there is no production.

$f_{1} \quad$ Probability density function of $\tau_{1}$.

$f_{2} \quad$ Probability density function of $\delta_{1}$.

$f_{3} \quad$ Probability density function of $\tau_{2}$.

$f_{4} \quad$ Probability density function of $\delta_{2}$.

ITB Expected number of items produced by Buffer machine.

ITO Expected number of items produced by Original machine.

$t_{\mathrm{O}} \quad$ Expected run time of Original machine.

$t_{\mathrm{B}} \quad$ Expected run time of Buffer machine.

\subsection{Problem definition}

A single-stage inventory problem on an infinite time horizon is considered with two machines (original and buffer) while only one runs at a time. Production starts at the beginning of the cycle by the original one, which may face the problem of disruption. When the original one breaks down, it will be bought under corrective maintenance immediately. During this time, production continues uninterruptedly by the buffered machine. The original one has a safe running period, i.e., whenever production commences, the system will run uninterruptedly for a period. After elapsing the safe period, disruption of the original machine may happen at any moment. The length of a corrective maintenance period, which generally depends on the intensity of the breakdown of the production system, is considered as a continuous random variable.

\subsection{Model formulation and analysis of the model}

Here, the offered "Safe period" $\alpha$ is assumed as a fixed time interval. According to the length of the $\alpha$, different cases may arise. As the production system works smoothly within the safe period, we discuss the cases whether the period lies within the production-run time or not. In this paper, we have assumed that maximum disruption situations may occur two times. Therefore, the following cases arise

Case 1: $\frac{t_{\mathrm{p}}}{3}<\alpha<\frac{t_{\mathrm{p}}}{2}$, the number of disruption of the original machine is at most two.

Case 2: $\frac{t_{\mathrm{p}}}{2} \leq \alpha<t_{\mathrm{p}}$, the number of disruption of the original machine is at most one.

Case 3: $t_{\mathrm{p}} \leq \alpha$, the disruption of the original machine is not occurred.

Case 1: $\frac{t_{\mathrm{p}}}{3}<\alpha<\frac{t_{\mathrm{p}}}{2}$

In this case, the first disruption of the original machine occurs at time $t=\tau_{1}$ after the end of the "Safe period" time limit. Now, two situations may arise: disruption occurs within production run-time $\left(t_{\mathrm{p}}\right)$ or after that time, i.e., Sub Case 1.1: $\alpha<\tau_{1}<t_{\mathrm{p}}$ and Sub Case 1.2: $t_{\mathrm{p}} \leq \tau_{1}$.

\section{Sub Case 1.1: $\alpha<\tau_{1}<t_{\mathrm{p}}$}

Here, the original machine works for the period $\left[0, \tau_{1}\right]$, and after that, the buffer machine continues the production process until the completion of the corrective maintenance $\left(\delta_{1}\right)$ of the original machine. Considering the range of $\tau_{1}$ and $\delta_{1}$, following three sub cases arise: Sub Case 1.1.1: $\tau_{1}+\delta_{1}<t_{\mathrm{p}}-\alpha$, Sub Case 1.1.2: $t_{\mathrm{p}}-\alpha \leq \tau_{1}+\delta_{1}<t_{\mathrm{p}}$ and Sub Case 1.1.3: $t_{\mathrm{p}} \leq \tau_{1}+\delta_{1}$. 
Sub Case 1.1.1: $\tau_{1}+\delta_{1}<t_{\mathrm{p}}-\alpha$

In this sub-case, there is the possibility for a second-time disruption of the original machine as the remaining production run time after the first corrective maintenance is greater than $\alpha$. Therefore, the following two situations can appear: Sub Case 1.1.1.1: $\tau_{1}+\delta_{1}+\tau_{2}<t_{\mathrm{p}}$ and Sub Case 1.1.1.2: $\tau_{1}+\delta_{1}+\tau_{2} \geq t_{\mathrm{p}}$.

\section{Sub Case 1.1.1.1: $\tau_{1}+\delta_{1}+\tau_{2}<t_{\mathrm{p}}$}

In this sub-case, the original machine again goes under the second disruption after running a period of length $\tau_{2}$ measured from the finish of the first corrective maintenance, but total production is still not completed. Therefore, the production is again continuing by the buffer machine, and the original one is sent for maintenance. According to the ranges of $\tau_{1}, \delta_{1}, \tau_{2}$ and $\delta_{2}$, two sub cases arise: Sub Case 1.1.1.1.1: $\tau_{1}+\delta_{1}+\tau_{2}+\delta_{2}<t_{\mathrm{p}}$ and Sub Case 1.1.1.1.2: $t_{\mathrm{p}} \leq \tau_{1}+\delta_{1}+\tau_{2}+\delta_{2}$.

All the sub-cases under Case 1 are exhibited in the following tree diagram:

$$
\text { Case } 1: \frac{t_{p}}{3}<\alpha<\frac{t_{p}}{2}
$$

Sub Case 1.1: $\alpha<\tau_{1}<t_{p}$

Sub Case 1.2: $t_{p} \leq \tau_{1}$

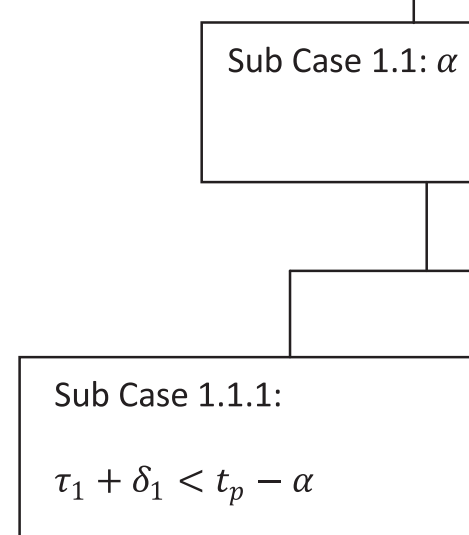

Sub Case 1.1.2:

Sub Case 1.1.3:

$$
t_{p}-\alpha \leq \tau_{1}+\delta_{1}<t_{p}
$$

$t_{p} \leq \tau_{1}+\delta_{1}$

Sub Case 1.1.1.1: $\tau_{1}+\delta_{1}+\tau_{2}<t_{p}$

Sub Case 1.1.1.2: $t_{p} \leq \tau_{1}+\delta_{1}+\tau_{2}$

Sub Case 1.1.1.1.1: $\tau_{1}+\delta_{1}+\tau_{2}+\delta_{2}<t_{p}$

Sub Case 1.1.1.1.2: $t_{p} \leq \tau_{1}+\delta_{1}+\tau_{2}+\delta_{2}$ 


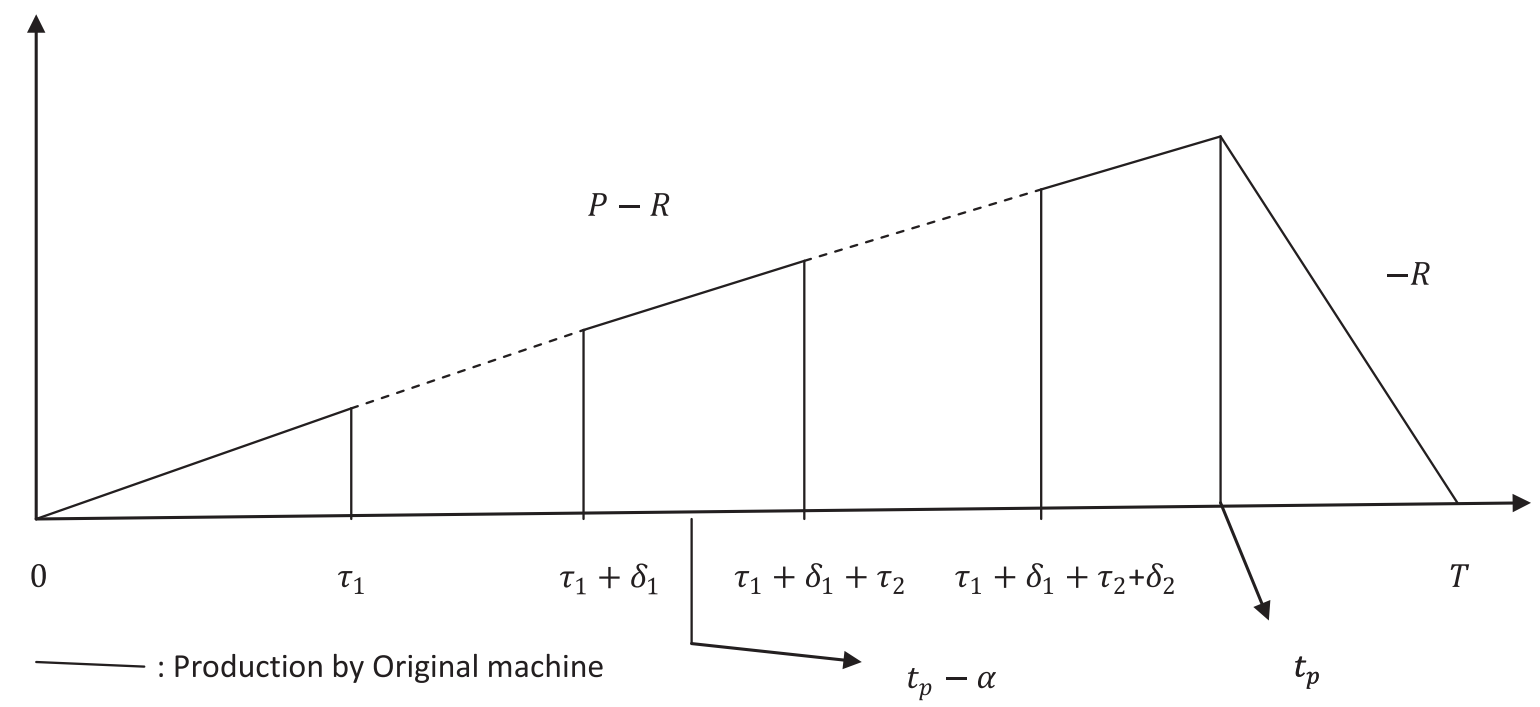

-... - : Production by Buffer machine

FiguRE 1. Inventory level (vertical axis) versus time (horizontal axis) for the Sub Case 1.1.1.1.1.

\section{Sub Case 1.1.1.1.1: $\tau_{1}+\delta_{1}+\tau_{2}+\delta_{2}<t_{\mathrm{p}}$}

In this sub-case, the original machine falls in the disruption at time $t=\tau_{1}$ and $t=\tau_{1}+\delta_{1}+\tau_{2}$ and it is immediately brought up under corrective maintenance in each time. The Buffer machine is used for the time interval $\left[\tau_{1}, \tau_{1}+\delta_{1}\right]$ and $\left[\tau_{1}+\delta_{1}+\tau_{2}, \tau_{1}+\delta_{1}+\tau_{2}+\delta_{2}\right]$ to continue the production system in the absence of the original one. Production is completed by the original machine when it runs for the third time during the period $\left[\tau_{1}+\delta_{1}+\tau_{2}+\delta_{2}, t_{\mathrm{p}}\right]$. The logistic diagram of this case is given in Figure 1.

Differential equation governing inventory level in the period $\left[0, t_{\mathrm{p}}\right]$ and $\left[t_{\mathrm{p}}, T\right]$ is given by respectively

$$
\frac{\mathrm{d} I_{1}}{\mathrm{~d} t}=P-R \quad \text { and } \quad \frac{\mathrm{d} I_{2}}{\mathrm{~d} t}=-R
$$

Solution of the differential equations with respect to the conditions $I_{1}(0)=0$ and $I_{2}(T)=0$ is given by respectively

$$
\begin{aligned}
& I_{1}(t)=(P-R) t \\
& I_{2}(t)=R(T-t) .
\end{aligned}
$$

Here, the inventory holding cost is

$$
\begin{aligned}
& h\left[\int_{0}^{t_{\mathrm{p}}} I_{1}(t) \mathrm{d} t+\int_{t_{\mathrm{p}}}^{T} I_{2}(t) \mathrm{d} t\right]=\frac{h(P-R) Q^{2}}{2 P R} . \\
& {\left[\text { By using } t_{\mathrm{p}}=\frac{Q}{P} \text { and } T=\frac{Q}{R}\right]}
\end{aligned}
$$




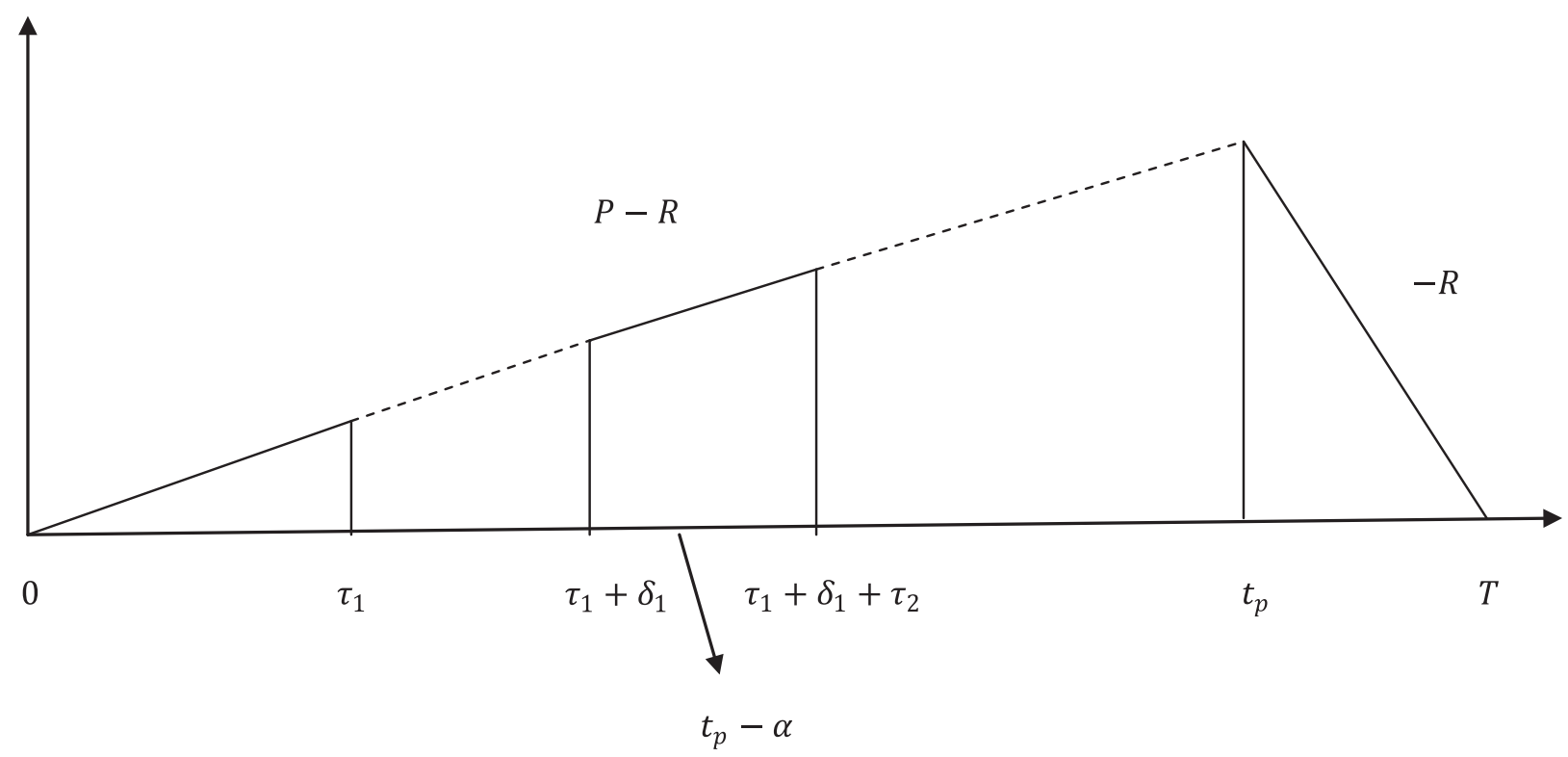

— : Production by Original machine

: Production by Buffer machine

FiguRE 2. Inventory level (vertical axis) versus time (horizontal axis) diagram for the Sub Case 1.1.1.1.2.

The buffer machine is used twice for the time intervals $\left[\tau_{1}, \tau_{1}+\delta_{1}\right]$ and $\left[\tau_{1}+\delta_{1}+\tau_{2}, \tau_{1}+\delta_{1}+\tau_{2}+\delta_{2}\right]$. So the buffer machine runs for total time $\left(\delta_{1}+\delta_{2}\right)$, which is equal to the total corrective maintenance period of the original machine. As it has production rate $P$, the number of items produced by it is $P\left(\delta_{1}+\delta_{2}\right)$.

\section{Sub Case 1.1.1.1.2: $t_{\mathrm{p}} \leq \tau_{1}+\delta_{1}+\tau_{2}+\delta_{2}$}

This sub-case differs from Sub Case 1.1.1.1.1 since buffer machine finishes the production when it runs during the second corrective maintenance period for the original one. Therefore, the original machine runs a total $\tau_{1}+\tau_{2}$ time, and the buffer one continues the rest of the production (Fig. 2). Hence, the number of items produced by the buffer machine is $P\left\{t_{\mathrm{p}}-\left(\tau_{1}+\tau_{2}\right)\right\}$.

\section{Sub Case 1.1.1.2: $\tau_{1}+\delta_{1}+\tau_{2} \geq t_{\mathrm{p}}$}

Here, the original machine faces only one disruption during the whole production run time. Therefore, the buffer machine continues the production during only the corrective maintenance period $\left[\tau_{1}, \tau_{1}+\delta_{1}\right]$ of the original one (Fig. 3). So the number of items produced by the buffer machine is $P \delta_{1}$.

Sub Case 1.1.2: $t_{\mathrm{p}}-\alpha<\tau_{1}+\delta_{1}<t_{\mathrm{p}}$

In this sub-case, second-time disruption is not possible for the original machine as $\left\{t_{\mathrm{p}}-\left(\tau_{1}+\delta_{1}\right)\right\}<\alpha$ but the original machine finishes the production when it runs second time after completion of corrective maintenance (Fig. 4). Here, the buffer machine runs for time $\delta_{1}$ and produces $P \delta_{1}$ number of items. 


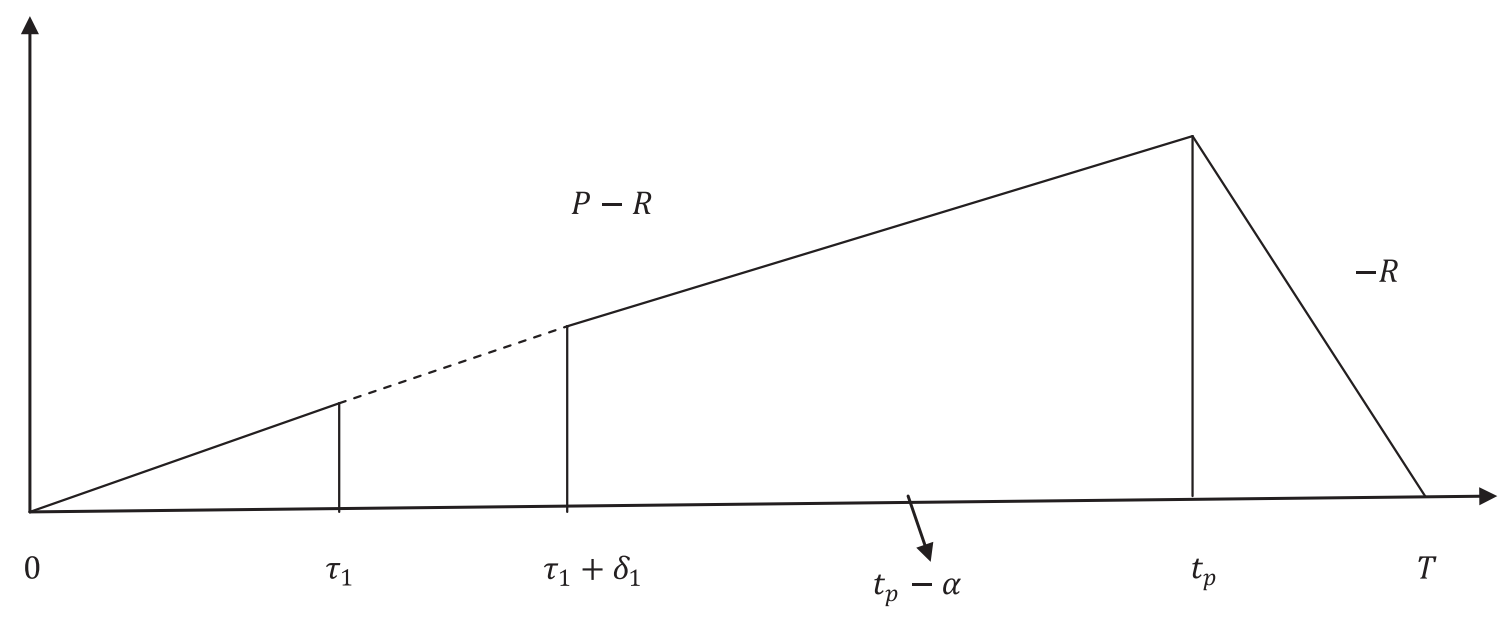

- Production by Original machine

: Production by Buffer machine

FiguRE 3. Inventory level (vertical axis) versus time (horizontal axis) diagram for the Sub Case 1.1.1.2.2.

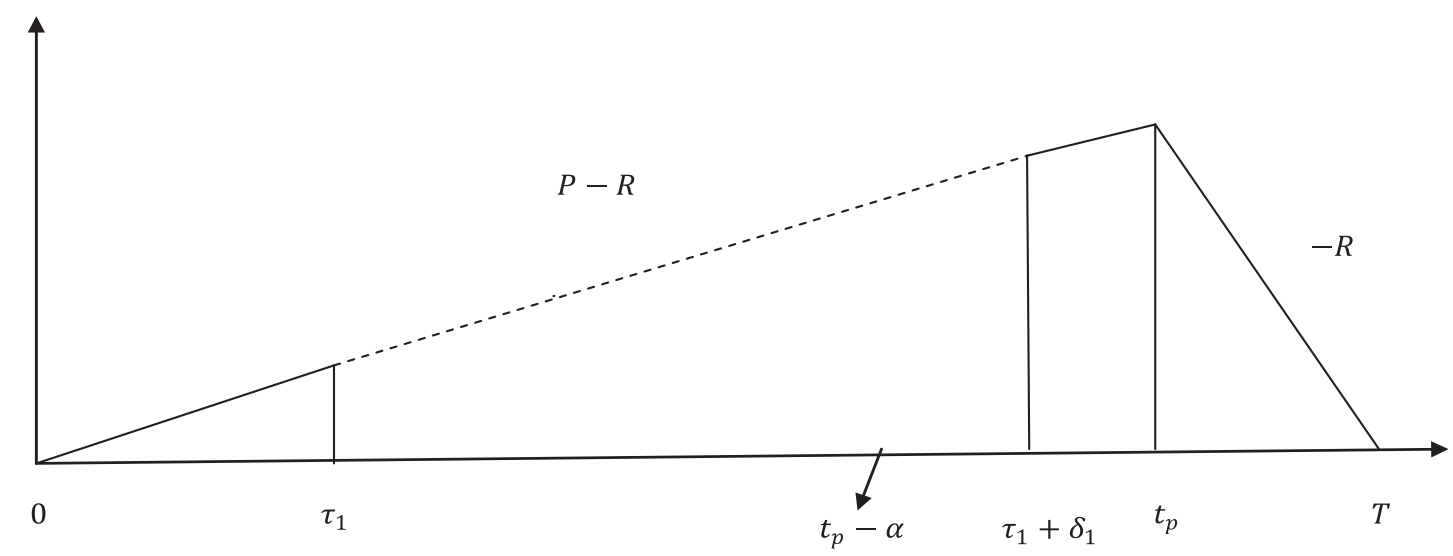

- Production by Original machine

: Production by Buffer machine

FIgURE 4. Inventory level (vertical axis) versus time (horizontal axis) diagram for the Sub Case 1.1.2.

\section{Sub Case 1.1.3: $t_{\mathrm{p}} \leq \tau_{1}+\delta_{1}$}

In this sub-case, only one disruption has occurred for the original machine at time $\tau_{1}$, and after that, the buffer machine finishes the rest of the production process as the corrective maintenance is not completed within the production time (Fig. 5). So, the number of items produced by the buffer machine is $P\left(t_{\mathrm{p}}-\tau_{1}\right)$. 


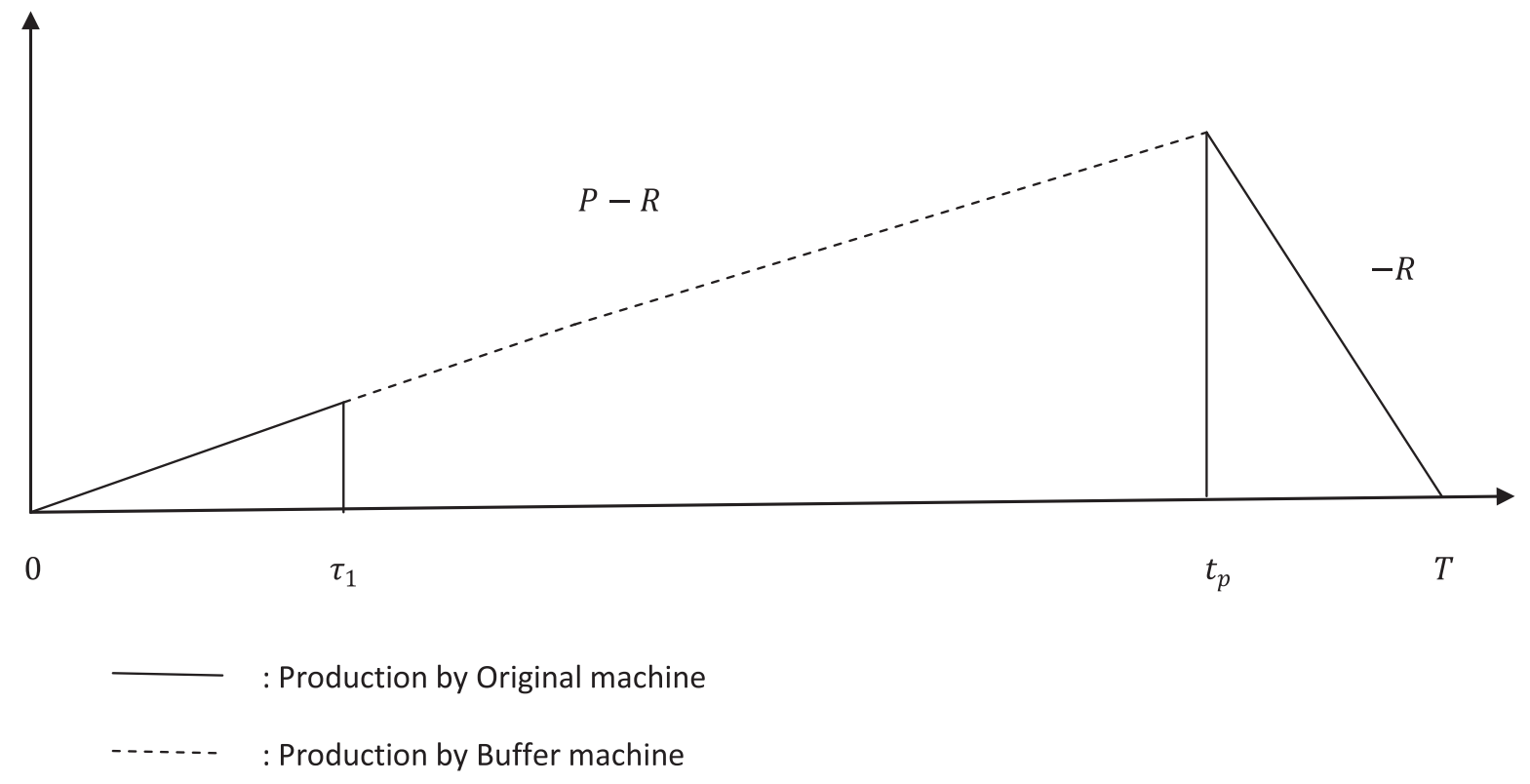

FiguRE 5. Inventory level (vertical axis) versus time (horizontal axis) diagram for the Sub Case 1.1.3.

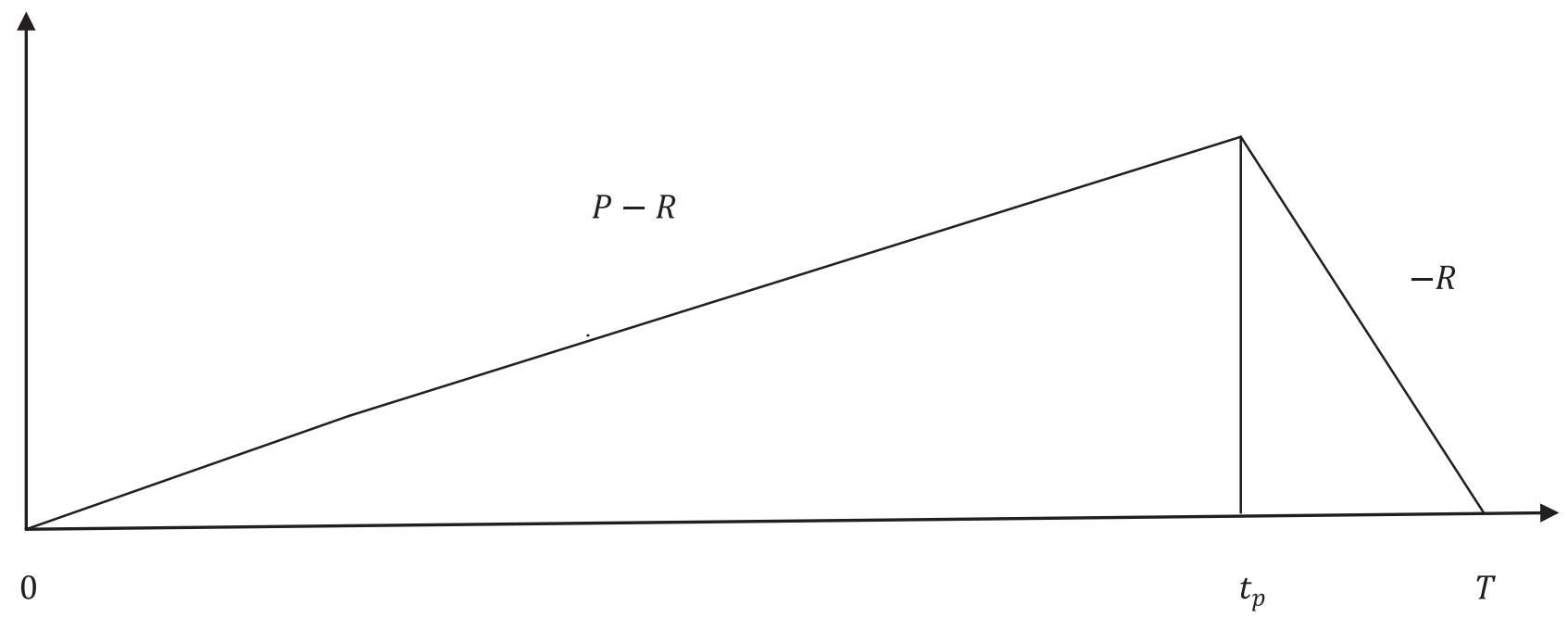

- Production by Original machine

FIGURE 6. Inventory level (vertical axis) versus time (horizontal axis) diagram for theSub Case 1.2.

\section{Sub Case 1.2: $t_{\mathrm{p}} \leq \tau_{1}$}

Here it is evident from the range of $\tau_{1}$ that no disruption is possible within the production time. So inventory plies up at a rate $P-R$ throughout the period $\left[0, t_{\mathrm{p}}\right]$ and then diminishes to zero at a rate $-R$ during the interval $\left[t_{\mathrm{p}}, T\right]$. In this sub-case, the buffer machine stays ideal throughout the cycle period (Fig. 6). 
So expected number of items produced by the buffer machine when $\alpha$ lies between $\frac{t_{\mathrm{p}}}{3}$ and $\frac{t_{\mathrm{p}}}{2}$ is given by the ITB1

$$
\begin{aligned}
\mathrm{ITB} 1= & \int_{\alpha}^{t_{\mathrm{p}}}\left(\left[\int _ { 0 } ^ { t _ { \mathrm { p } } - \alpha - \tau _ { 1 } } \left\langle\int _ { \alpha } ^ { t _ { \mathrm { p } } - ( \tau _ { 1 } + \delta _ { 1 } ) } \left\{\int_{0}^{t_{\mathrm{p}}-\left(\tau_{1}+\delta_{1}+\tau_{2}\right)} P\left(\delta_{1}+\delta_{2}\right) f_{4} \mathrm{~d} \delta_{2}\right.\right.\right.\right. \\
& \left.\left.\left.+\int_{t_{\mathrm{p}}-\left(\tau_{1}+\delta_{1}+\tau_{2}\right)}^{N_{1}}\left(Q-P \tau_{1}-P \tau_{2}\right) f_{4} \mathrm{~d} \delta_{2}\right\} f_{3} \mathrm{~d} \tau_{2}+\int_{t_{\mathrm{p}}-\left(\tau_{1}+\delta_{1}\right)}^{\infty} P \delta_{1} f_{3} \mathrm{~d} \tau_{2}\right\rangle f_{2} \mathrm{~d} \delta_{1}\right] \\
& \left.+\left[\int_{t_{\mathrm{p}}-\alpha-\tau 1}^{t_{\mathrm{p}}-\tau_{1}} P \delta_{1} f_{2} \mathrm{~d} \delta_{1}\right]+\left[\int_{t_{\mathrm{p}}-\tau_{1}}^{M_{1}}\left(Q-P \tau_{1}\right) f_{2} \mathrm{~d} \delta_{1}\right]\right) f_{1} \mathrm{~d} \tau_{1}
\end{aligned}
$$

and the expected corrective maintenance time period ECMT1 is given below

$$
\begin{aligned}
\operatorname{ECMT} 1= & \int_{\alpha}^{t_{\mathrm{p}}}\left(\left[\int _ { 0 } ^ { t _ { \mathrm { p } } - \alpha - \tau _ { 1 } } \left\langle\int_{\alpha}^{t_{\mathrm{p}}-\left(\tau_{1}+\delta_{1}\right)}\left\{\int_{0}^{t_{\mathrm{p}}-\left(\tau_{1}+\delta_{1}+\tau_{2}\right)}\left(\delta_{1}+\delta_{2}\right) f_{4} \mathrm{~d} \delta_{2}+\int_{t_{\mathrm{p}}-\left(\tau_{1}+\delta_{1}+\tau_{2}\right)}^{N_{1}}\left(\delta_{1}+\delta_{2}\right) f_{4} \mathrm{~d} \delta_{2}\right\} f_{3}\right.\right.\right. \\
& \left.\left.\left.\times \mathrm{d} \tau_{2}+\int_{t_{\mathrm{p}}-\left(\tau_{1}+\delta_{1}\right)}^{\infty} \delta_{1} f_{3} \mathrm{~d} \tau_{2}\right\rangle f_{2} \mathrm{~d} \delta_{1}\right]+\left[\int_{t_{\mathrm{p}}-\alpha-\tau_{1}}^{\tau_{p}-\tau_{1}} \delta_{1} f_{2} \mathrm{~d} \delta_{1}\right]+\left[\int_{t_{\mathrm{p}}-\tau_{1}}^{M_{1}} \delta_{1} f_{2} \mathrm{~d} \delta_{1}\right]\right) f_{1} \mathrm{~d} \tau_{1}
\end{aligned}
$$

Therefore the expected maintenance cost is $C_{\mathrm{m}}$ ECMT1.

In this case, the total expected cost is the sum of the setup, holding, and production cost by the original machine, production cost by the buffer machine, and cost for corrective maintenance, i.e.,

$$
\mathrm{ETC} 1=k+\frac{h(P-R) Q^{2}}{2 P R}+C_{1}(Q-\mathrm{ITB} 1)+C_{2} \mathrm{ITB} 1+C_{\mathrm{m}} \text { ECMT1. }
$$

Then expected total cost per unit time is denoted by EATC1 and described by

$$
\mathrm{EATC} 1=\mathrm{ETC} 1 / T \quad \text { where } \quad T=\frac{Q}{R} .
$$

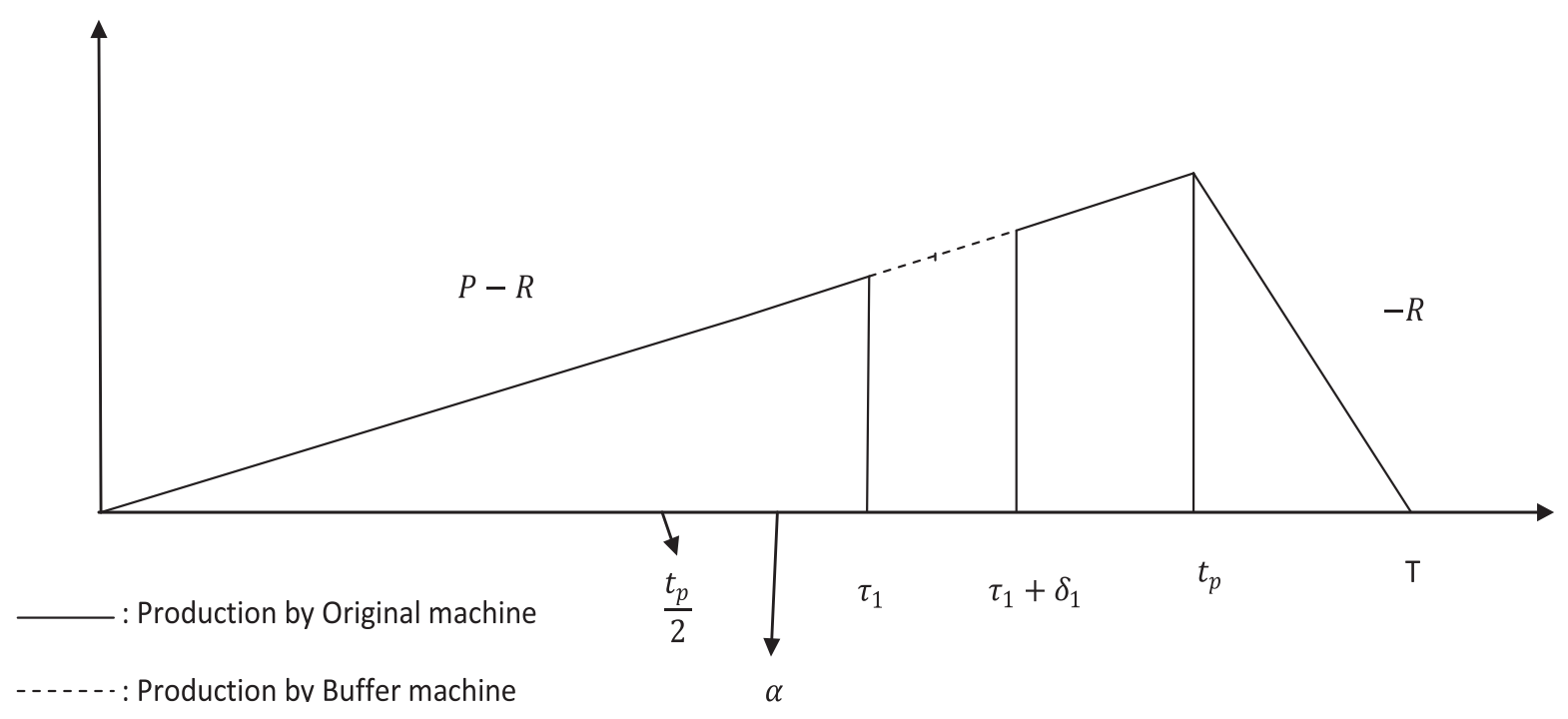

FiguRE 7. Inventory level (vertical axis) versus time (horizontal axis) for the Sub Case 2.1.1. 
Case 2: $\frac{t_{\mathrm{p}}}{2} \leq \alpha<t_{\mathrm{p}}$

Under this circumstance, at most one disruption of the original machine is possible. Considering possible ranges of the random variable $\tau_{1}$, two sub cases arise: Sub Case 2.1: $\alpha<\tau_{1}<t_{\mathrm{p}}$ and Sub Case 2.2: $t_{\mathrm{p}} \leq \tau_{1}$.

\section{Sub Case 2.1: $\alpha<\tau_{1}<t_{\mathrm{p}}$}

In this sub-case, the buffer machine starts production immediately after the broken down of the original one, but the total running time is dependent on the corrective maintenance period. The time by which the original machine will be ready for production in the inventory cycle is given by $\tau_{1}+\delta_{1}$. Then two possible sub-cases are Sub Case 2.1.1: $\tau_{1}+\delta_{1}<t_{\mathrm{p}}$ and Sub Case 2.1.2: $t_{\mathrm{p}} \leq \tau_{1}+\delta_{1}$.

All the sub cases under Case 2 are shown in the following tree diagram:

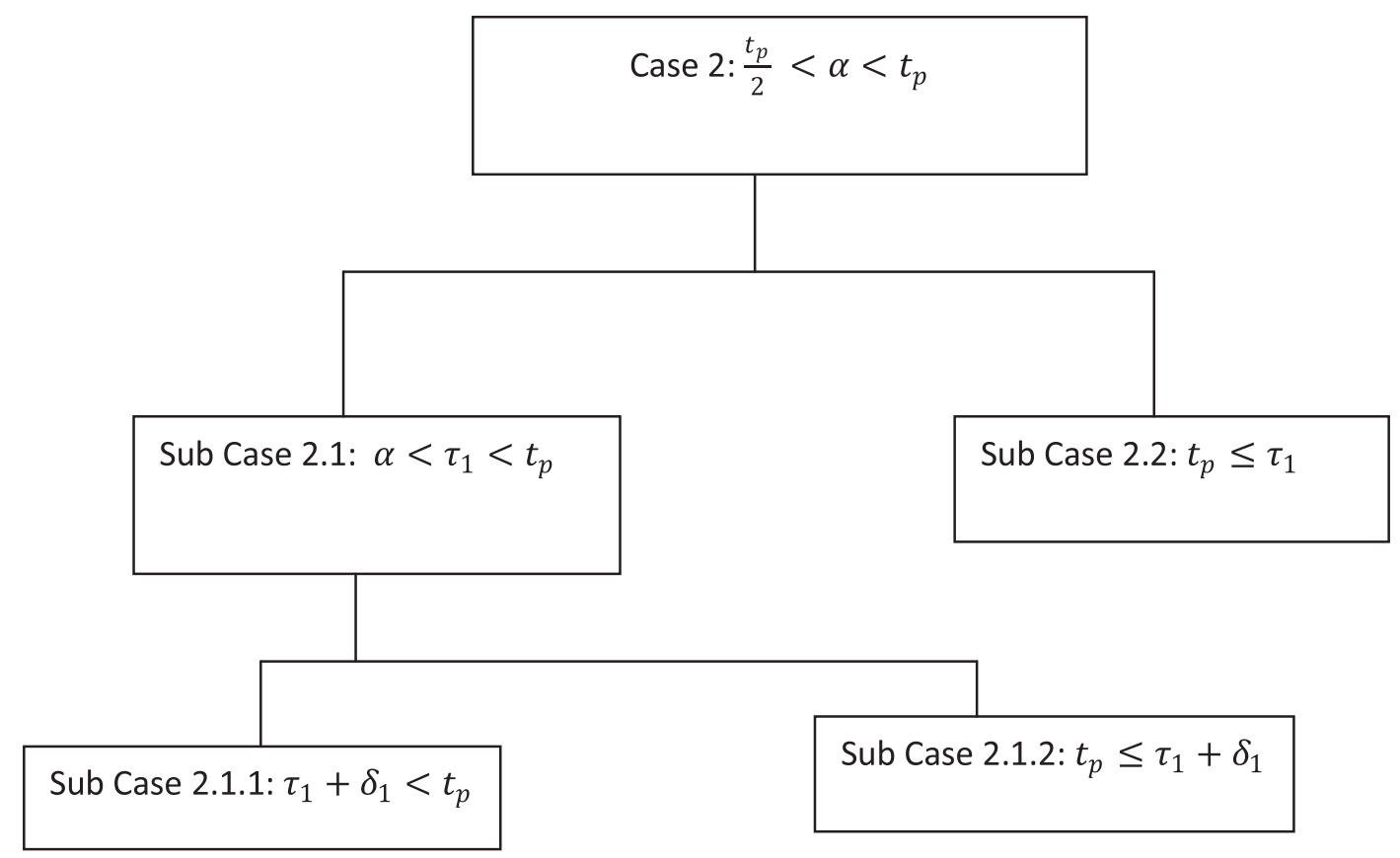

\section{Sub Case 2.1.1: $\tau_{1}+\delta_{1}<t_{\mathrm{p}}$}

In this sub-case, the original machine breaks down at time $t=\tau_{1}$, and it again runs after time $\delta_{1}$ within the production run time. During the corrective maintenance period $\delta_{1}$, the buffer machine continues the production and the number of items produced by $P \delta_{1}$ (Fig. 7).

Sub Case 2.1.2: $t_{\mathrm{p}} \leq \tau_{1}+\delta_{1}$

This sub-case is different from the above concerning the corrective maintenance of the original machine. Here the maintenance period is not completed within the production run time (Fig. 8). After the breakdown of the original machine, the buffer machine finishes the rest of the production by the period $\left[\tau_{1}, t_{\mathrm{p}}\right]$.

\section{Sub Case 2.2: $t_{\mathrm{p}} \leq \tau_{1}$}

This sub case is similar to the Sub Case 1.2.

The expected number of items produced by the buffer machine when $\alpha$ lies between $\frac{t_{\mathrm{p}}}{2}$ and $t_{\mathrm{p}}$ is given by

$$
\operatorname{ITB} 2=\int_{\alpha}^{t_{\mathrm{p}}}\left[\left\{\int_{0}^{t_{\mathrm{p}}-\tau_{1}} P \delta_{1} f_{2} \mathrm{~d} \delta_{1}\right\}+\left\{\int_{t_{\mathrm{p}}-\tau_{1}}^{M_{1}}\left(Q-P \tau_{1}\right) f_{2} \mathrm{~d} \delta_{1}\right\}\right] f_{1} \mathrm{~d} \tau_{1}
$$




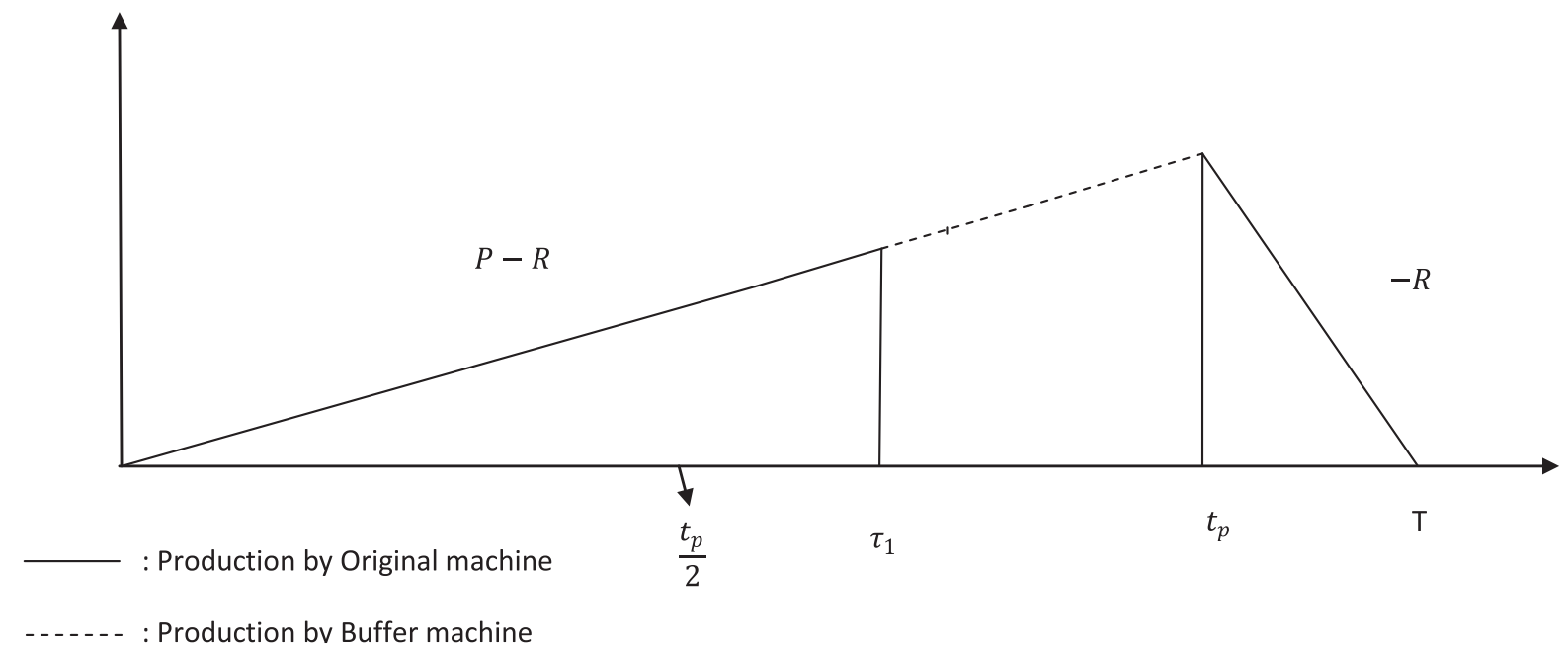

FiguRE 8. Inventory level (vertical axis) versus time (horizontal axis) for the Sub Case 2.1.2.

and the expected corrective maintenance period ECMT2 is

$$
\operatorname{ECMT} 2=\int_{\alpha}^{t_{\mathrm{p}}}\left[\left\{\int_{0}^{t_{\mathrm{p}}-\tau_{1}} \delta_{1} f_{2} \mathrm{~d} \delta_{1}\right\}+\left\{\int_{t_{\mathrm{p}}-\tau_{1}}^{M_{1}} \delta_{1} f_{2} \mathrm{~d} \delta_{1}\right\}\right] f_{1} \mathrm{~d} \tau_{1} .
$$

Therefore, the expected total cost for this case is

$$
\mathrm{ETC} 2=k+C_{\mathrm{m}} \mathrm{ECMT} 2+\frac{h(P-R) Q^{2}}{2 P R}+C_{1}(Q-\mathrm{ITB} 2)+C_{2} \mathrm{ITB} 2
$$

and the expected average total cost per unit time is given by

$$
\mathrm{EATC} 2=\mathrm{ETC} 2 / T \quad \text { where } \quad T=\frac{Q}{R}
$$

\section{Case 3: $t_{\mathrm{p}} \leq \alpha$}

In this case, no disruption is possible for the original machine as the "Safe Period" exceeds production run time. So there is no use of buffer machine.

Total cost is composed of the sum of three components: set-up cost, holding cost, and production cost of the items produced by the original machine. So total cost is given by

$$
\mathrm{TC}=k+\frac{h(P-R) Q^{2}}{2 P R}+C_{1} Q
$$

One interesting fact is that the expression (2.12) can be obtained from the relation (2.6) by putting $C_{\mathrm{m}}=0$ and ITB1 $=0$. Also, this can be obtained from (2.10) by putting $C_{\mathrm{m}}=0$ and ITB2 $=0$.

The average total cost per unit time is $\mathrm{ATC}=\mathrm{TC} / T$, where $T=\frac{Q}{R}$. 
In this paper, it is assumed that the random variables $\tau_{1}, \tau_{2}, \delta_{1}$ and $\delta_{2}$ follow the uniform distribution and given by

$$
\begin{aligned}
& f_{1}=f\left(\tau_{1}\right)= \begin{cases}\frac{1}{a-\alpha} & \text { when } \alpha<\tau_{1}<a \\
0 & \text { else where }\end{cases} \\
& f_{3}=f\left(\tau_{2}\right)= \begin{cases}\frac{1}{b-\alpha} & \text { when } \alpha<\tau_{2}<b \\
0 & \text { else where }\end{cases} \\
& f_{2}=f\left(\delta_{1}\right)= \begin{cases}\frac{1}{M_{1}} & \text { when } 0<\delta_{1}<M_{1} \\
0 & \text { else where }\end{cases} \\
& f_{4}=f\left(\delta_{2}\right)= \begin{cases}\frac{1}{N_{1}} & \text { when } 0<\delta_{2}<N_{1} \\
0 & \text { else where. }\end{cases}
\end{aligned}
$$

Let $a=\alpha+e_{1}, b=\alpha+e_{2}$ and $\alpha=\frac{\beta Q}{P}$. As a result, the range of the Cases $1-3$ converts to $\frac{1}{3} \leq \beta \leq \frac{1}{2}$ (Case 1 ), $\frac{1}{2} \leq \beta \leq 1$ (Case 2) and $\beta \geq 1$ (Case 3).

Now, using the probability density function of the random variables, the expected average cost (2.7) for the Case 1 can be simplified as

$$
\mathrm{EATC} 1=W_{1}+W_{2} Q+W_{3} Q^{2}-W_{4} Q^{3}-W_{5} Q^{4}+\frac{W_{6}}{Q}
$$

where

$$
\begin{aligned}
& W_{1}=\frac{R\left(2 C_{1} e_{1} P+C_{\mathrm{m}} M_{1}(1-\beta)\right)}{2 e_{1} P}, \quad W_{2}=\frac{\left\{e_{1} h(P-R)+\left(C_{2}-C_{1}\right) R(1-\beta)^{2}\right\}}{2 e_{1} P}, \\
& W_{3}=\frac{R(1-\beta)\left\{C_{\mathrm{m}} N_{1}\left(7 \beta^{2}-5 \beta+1\right)-2\left(C_{2}-C_{1}\right) e_{2} P(1-\beta)^{2}\right\}}{12 e_{1} e_{2} M_{1} P^{3}}, \\
& W_{4}=\frac{\left(C_{2}-C_{1}\right) R(1-\beta)\left(15 \beta^{3}-17 \beta^{2}+7 \beta-1\right)}{24 e_{1} e_{2} M_{1} N_{1} P^{3}}, \\
& W_{5}=\frac{\left(C_{2}-C_{1}\right) R(1-\beta)\left(31 \beta^{4}-49 \beta^{3}+31 \beta^{2}-9 \beta+1\right)}{120 e_{1} e_{2} M_{1} N_{1} P^{4}}, \quad W_{6}=k R .
\end{aligned}
$$

Similarly, for Case 2 and Case 3, the cost functions (2.11) and (2.13) can be written respectively as

$$
\operatorname{EATC} 2=E_{1}+E_{2} Q-E_{3}^{2} Q+\frac{E_{4}}{Q}
$$

where

$$
\begin{aligned}
& E_{1}=\frac{R\left(2 C_{1} e_{1} P+C_{\mathrm{m}} M_{1}(1-\beta)\right)}{2 e_{1} P}, \quad E_{2}=\frac{\left\{e_{1} h(P-R)+\left(C_{2}-C_{1}\right) R(1-\beta)^{2}\right\}}{2 e_{1} P}, \\
& E_{3}=\frac{\left(C_{2}-C_{1}\right) R(1-\beta)^{3}}{6 e_{1} M_{1} P^{2}}, \quad E_{4}=k R
\end{aligned}
$$

and

$$
\mathrm{ATC}=C_{1} R+\frac{k R}{Q}+\frac{h Q(P-R)}{2 P} .
$$

Proposition 2.1. For Case 1, the expected average cost function is minimum at $Q=Q_{1}$, if the following inequality is satisfied.

$$
6 W_{3}-12 W_{4} Q_{1}-20 W_{5} Q_{1}^{2}+\frac{2 W_{2}}{Q_{1}}>0 .
$$


Proof. Differentiating equation (2.14) with respect to $Q$ we have

$$
\frac{\mathrm{d}}{\mathrm{d} Q}(\mathrm{EATC} 1)=W_{2}+2 W_{3} Q-3 W_{4} Q^{2}-4 W_{5} Q^{3}-\frac{W_{6}}{Q^{2}}
$$

and

$$
\frac{\mathrm{d}^{2}}{\mathrm{~d} Q^{2}}(\mathrm{EATC} 1)=2 W_{3}-6 W_{4} Q-12 W_{5} Q^{2}+\frac{2 W_{6}}{Q^{3}} .
$$

For necessary condition of optimization, we have $\frac{\mathrm{d}}{\mathrm{d} Q}(\mathrm{EATC} 1)=0$. Let $Q=Q_{1}$ be the solution of the previous equation. Then $Q_{1}$ satisfies the following equality $W_{2}+2 W_{3} Q_{1}-3 W_{4} Q_{1}^{2}-4 W_{5} Q_{1}^{3}=\frac{W_{6}}{Q_{1}^{2}}$. From the sufficient condition of optimality of cost function, we find that $Q_{1}$ will be optimal lot size if $\left.\frac{\mathrm{d}^{2}}{\mathrm{~d}^{2}}(\mathrm{EATC} 1)\right|_{Q^{2} Q_{1}}>0$.

Now,

$$
\begin{aligned}
\left.\frac{\mathrm{d}^{2}}{\mathrm{~d} Q^{2}}(\text { EATC } 1)\right|_{Q=Q_{1}} & =2 W_{3}-6 W_{4} Q_{1}-12 W_{5} Q_{1}^{2}+\frac{2 W_{6}}{Q_{1}^{3}} \\
& =2 W_{3}-6 W_{4} Q_{1}-12 W_{5} Q_{1}^{2}+\frac{2}{Q_{1}}\left(\frac{W_{6}}{Q_{1}^{2}}\right) .
\end{aligned}
$$

Substituting $\frac{W_{6}}{Q_{1}^{2}}$ by $W_{2}+2 W_{3} Q_{1}-3 W_{4} Q_{1}^{2}-4 W_{5} Q_{1}^{3}$, and after algebraic manipulation we have

$$
\left.\frac{\mathrm{d}^{2}}{\mathrm{~d} Q^{2}}(\mathrm{EATC} 1)\right|_{Q=Q_{1}}=6 W_{3}-12 W_{4} Q_{1}-20 W_{5} Q_{1}^{2}+\frac{2 W_{2}}{Q_{1}} .
$$

So EATC1 is minimum at $Q=Q_{1}$ if $\left.\frac{\mathrm{d}^{2}}{\mathrm{~d}^{2}}(\mathrm{EATC} 1)\right|_{Q=Q_{1}}>0$ i.e., if

$$
6 W_{3}-12 W_{4} Q_{1}-20 W_{5} Q_{1}^{2}+\frac{2 W_{2}}{Q_{1}}>0 .
$$

Hence the proposition is established.

Proposition 2.2. For Case 2, the expected average cost function is minimum at $Q=Q_{2}$ if the inequality $Q_{2}<\frac{E_{2}}{3 E_{3}}$ is satisfied.

Proof. Differentiating equation (2.15) with respect to $Q$ we have

$$
\begin{aligned}
\frac{\mathrm{d}}{\mathrm{d} Q}(\text { EATC2 }) & =E_{2}-2 E_{3} Q-\frac{E_{4}}{Q^{2}}, \\
\text { and } \frac{\mathrm{d}^{2}}{\mathrm{~d} Q^{2}}(\text { EATC2 }) & =-2 E_{3}+\frac{2 E_{4}}{Q^{3}} .
\end{aligned}
$$

For necessary condition of optimization, we have $\frac{\mathrm{d}}{\mathrm{d} Q}$ (EATC2) $=0$. Let $Q=Q_{2}$ be the solution of the previous equation. Then $Q_{2}$ satisfies the equality $E_{2}-2 E_{3} Q_{2}=\frac{E_{4}}{Q_{2}^{2}}$. $Q_{2}$ will be optimal lot size if it satisfies the condition $\frac{\mathrm{d}^{2}}{\mathrm{~d} Q^{2}}\left(\right.$ EATC2) $\left.\right|_{Q=Q_{2}}>0$.

Now

$$
\begin{aligned}
& \left.\frac{\mathrm{d}^{2}}{\mathrm{~d} Q^{2}}(\text { EATC2 })\right|_{Q=Q_{2}}=-2 E_{3}+\frac{2 E_{4}}{Q_{2}^{3}} \\
& \left.\frac{\mathrm{d}^{2}}{\mathrm{~d} Q^{2}}(\text { EATC2 })\right|_{Q=Q_{2}}=\frac{2}{Q_{2}}\left(\frac{E_{4}}{Q_{2}^{2}}-E_{3} Q_{2}\right) .
\end{aligned}
$$


Replacing $\frac{E_{4}}{Q_{2}^{3}}$ by $E_{2}-2 E_{3} Q_{2}$, we have

$$
\left.\frac{\mathrm{d}^{2}}{\mathrm{~d} Q^{2}}(\text { EATC2 })\right|_{Q=Q_{2}}=\frac{2}{Q_{2}}\left(E_{2}-3 E_{3} Q_{2}\right) .
$$

Therefore, expected average total cost function is minimum at $Q=Q_{2}$ if $\frac{\mathrm{d}^{2}}{\mathrm{~d} Q^{2}}$ (EATC2) is positive at $Q=Q_{2}$, i.e., when $Q_{2}<\frac{E_{2}}{3 E_{3}}$. It should be noted that both $E_{2}$ and $E_{3}$ are positive since

$$
C_{2}>C_{1} \text { and } \beta<1 \text {. }
$$

Hence the proof.

Proposition 2.3. For Case 3, the average total cost function is minimum at $Q=Q^{*}$.

Proof. The necessary condition for minimization for this case is given by $\frac{\mathrm{d}}{\mathrm{d} Q}(\mathrm{ATC})=0$. Differentiating equation (2.16) with respect to $Q$ and equating the obtained expression to zero we get optimal lot size $Q=\sqrt{\frac{2 k P R}{h(P-R)}}$. Again, $\frac{\mathrm{d}^{2}}{\mathrm{~d} Q^{2}}($ ATC $)=\left\{\frac{h(P-R)}{P}\right\}^{\frac{3}{2}} \frac{1}{\sqrt{2 k R}}$ when $Q=Q^{*},=>\frac{\mathrm{d}^{2}}{\mathrm{~d}^{2}}($ ATC $)>0$ since $P>R$.

Hence the proof.

\section{NUMERICAL ANALYSIS}

The following numerically data is used to test the validity and applicability of the proposed model:

Production rate $P=1000$ units/time, demand rate $R=600$ units/time, setup cost $k=\$ 600$ per setup, production cost for the original machine $C_{1}=\$ 1.5$ per unit item, production cost for the buffer machine $C_{2}=\$ 2$ per unit item, corrective maintenance cost $C_{\mathrm{m}}=\$ 2$ per unit time, holding cost $h=\$ 1.0$ per unit per unit time, $e_{1}=0.5, e_{2}=0.5$, upper bound of the first corrective maintenance period $M=0.75$, upper bound of the second corrective maintenance period $N=0.75$.

\section{Case 1: When $\alpha$ lies between $\frac{t_{\mathrm{p}}}{3}$ and $\frac{t_{\mathrm{p}}}{2}$}

Here, we consider $\beta=0.45$ i.e., $\alpha=0.45 t_{\mathrm{p}}$. The optimal results for this case are discussed in the Table 2 .

The sufficient condition of the optimality is also satisfied since $\frac{\mathrm{d}^{2}}{\mathrm{~d} Q^{2}}$ (EATC1) at $Q=Q^{*}$ is given by $0.000266>0$. Also, the graphical representation of the expected average total cost (EATC1) function (Fig. 9) is convex. From Table 2, we observe that the buffer machine used $24 \%$ of the production run time for this case.

\section{Case 2: When $\alpha$ lies between $\frac{t_{\mathrm{p}}}{2}$ and $t_{\mathrm{p}}$}

Here, we consider $\beta=0.8$ i.e., $\alpha=0.8 t_{\mathrm{p}}$. The optimal results for this case are discussed in the Table 3 .

The results of Table 3 are optimal since the value of $\frac{\mathrm{d}^{2}}{\mathrm{~d} Q^{2}}$ (EATC1) at $Q=Q^{*}$ is given by $0.000317>0$. Also, we can say by graphically from Figure 10 that the expected average total cost (EATC2) function is unimodal. From the Table 3 , we observe that the buffer machine used $4.6 \%$ of the production run time for this case.

\section{Case 3: When $\alpha$ is greater than or equal to $t_{\mathrm{p}}$}

In this case there is no disruption possible for original machine within production time. The optimal results for this case are discussed in the Table 4 .

The value of $\frac{\mathrm{d}^{2}}{\mathrm{~d} Q^{2}}(\mathrm{ATC})$ at $Q=Q^{*}$ is given by $0.000298>0$, which is the condition of optimality. Again, Figure 11 deals that the average total cost (ATC) function is unimodal. 
TABle 2. Optimal results of Case 1.

\begin{tabular}{ll}
\hline \hline Order quantity & $Q^{*}=1286.80$ unit \\
Expected number of items produced by original machine & $\mathrm{ITO}^{*}=972.25 \mathrm{unit}$ \\
Expected number of buffer item produced & $\mathrm{ITB}^{*}=314.55 \mathrm{unit}$ \\
Cycle length & $T^{*}=2.14$ unit \\
Production run time & $t_{\mathrm{P}}^{*}=1.29$ unit \\
Expected run time of original machine & $t_{\mathrm{O}}^{*}=0.98$ unit \\
Expected run time of buffer machine & $t_{\mathrm{B}}^{*}=0.31$ unit \\
Expected average total cost & EATC1 $1^{*}=\$ 1511.01$ \\
\hline
\end{tabular}

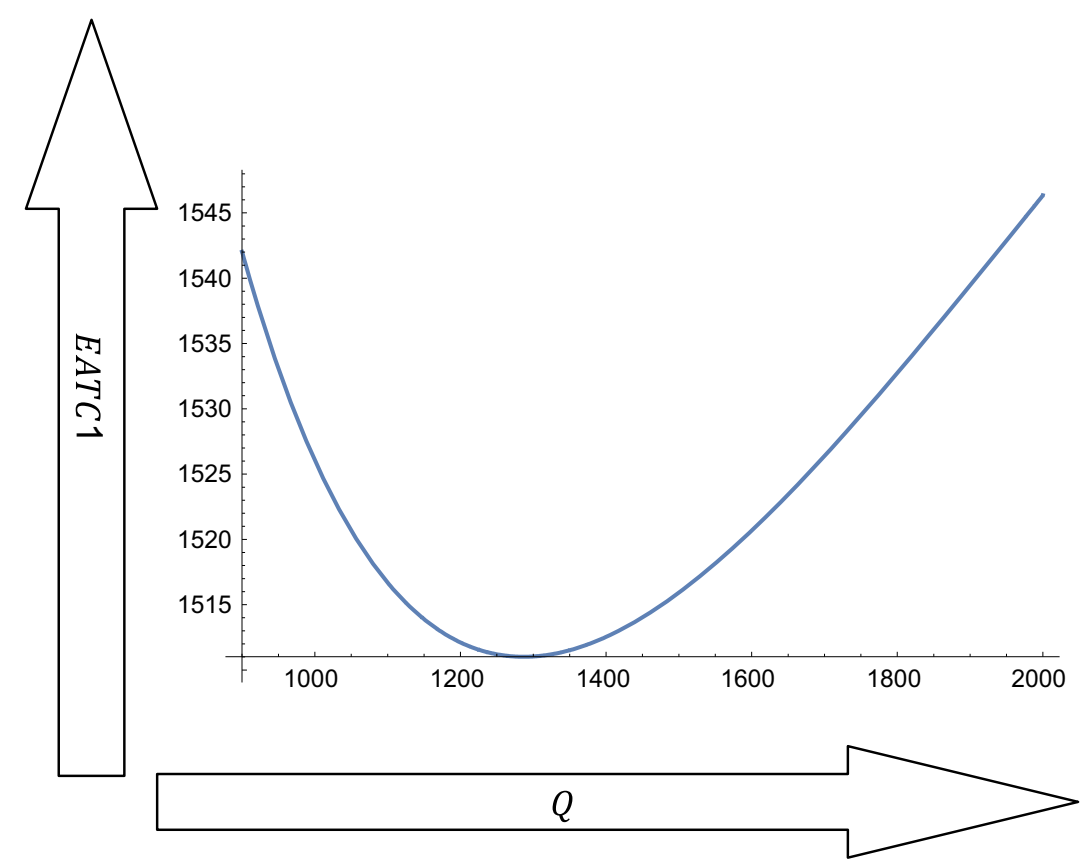

Figure 9. Expected average total cost versus lot size for Case 1.

TABLE 3. Optimal results of Case 2.

\begin{tabular}{ll}
\hline \hline Order quantity & $Q^{*}=1311.80$ unit \\
Expected number of items produced by original machine & $\mathrm{ITO}^{*}=1250.99$ unit \\
Expected number of buffer item produced & $\mathrm{ITB}^{*}=60.81$ unit \\
Cycle length & $T^{*}=2.19$ unit \\
Production run time & $t_{\mathrm{P}}^{*}=1.31$ unit \\
Expected run time of original machine & $t_{\mathrm{O}}^{*}=1.25$ unit \\
Expected run time of buffer machine & $t_{\mathrm{B}}^{*}=0.06$ unit \\
Expected average total cost & EATC2 $=\$ 1450.88$ \\
\hline
\end{tabular}




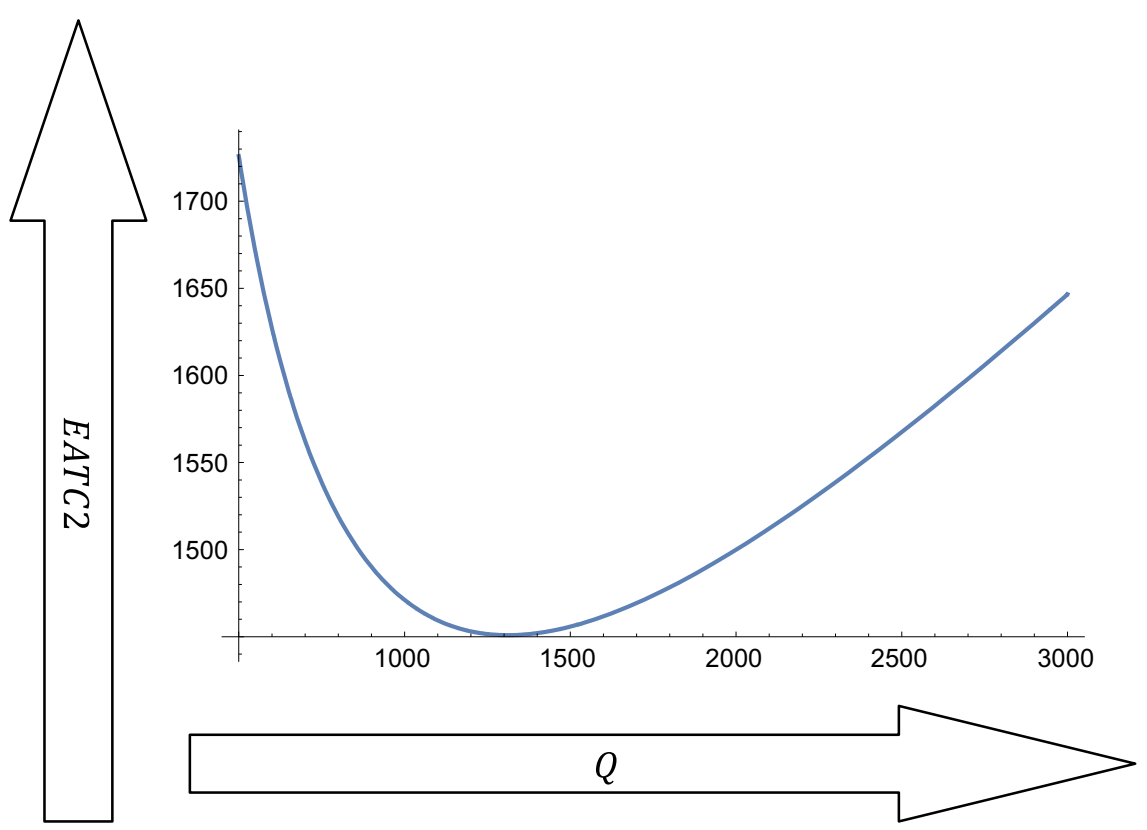

FiguRE 10. Expected average total cost versus lot size for Case 2.

TABLE 4. Optimal results of Case 3.

\begin{tabular}{ll}
\hline \hline Order quantity & $Q^{*}=1341.64$ unit \\
Cycle length & $T^{*}=2.24$ unit \\
Production run time & $t_{\mathrm{p}}^{*}=1.34$ unit \\
Average total cost & $\mathrm{ATC}^{*}=\$ 1436.66$ \\
\hline
\end{tabular}

\section{Observations}

(1) From the numerical results of Cases 1-3, we find that that the expected average cost reduces as the working period of the buffer machine reduces.

(2) When the safe period of production system increases, the ordering lot sizes along with the cycle length increase in the fixed demand rate.

(3) In Case 1 buffer machine is used $19.4 \%$ more than Case 2 concerning the production run time, but the expected average total cost is increased by only $4.1 \%$.

All the numerical calculations have been done with the help of the Software "Mathematica 9".

\section{Sensitivity ANALYSiS}

In this section, we test the feasibility of the developed model. We will examine the behavior of the expected average total cost (EATC1), lot size $(Q)$, the expected number of items produced by the buffer (ITB1), and original machine (ITO1) when values of different parameters are altered. It should be noted that the Safe period of the original machine may fall in a different region of the time horizon of the inventory cycle. As Case 1 is comparatively complicated than the other cases, here we only discuss the sensitivity analysis of Case 1. 


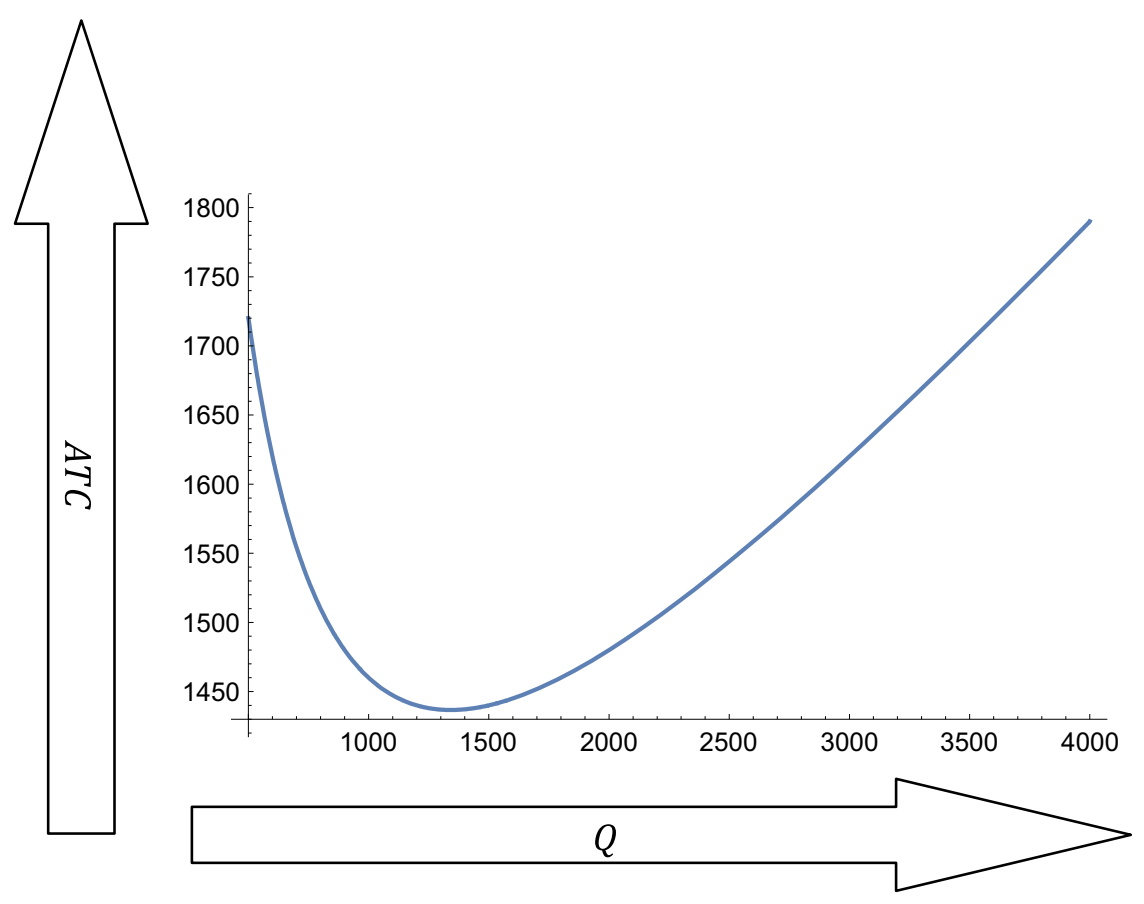

Figure 11. Average total cost versus lot size for Case 3.

From Figure 12a, we observe that EATC1 and ITB1 are decreasing, and $Q$ and ITO1 are increasing with the increasing value of $\beta$. As $\beta$ increases, the working period of the buffer machine reduces. The produced items by the buffer machine reduce if the values of $\beta$ increases. Consequently, the value EATC1 decreases since the cost of items produced by the buffer machine are more than that of the original machine.

When the production rate $(P)$ increases, $Q$ decreases rapidly. In this situation, the EATC1 increases, and the ITO1 and ITB1 decrease, where the decreasing rate of ITO1 more than ITB1 (Fig. 12b). As the production cost of a unit by buffer machine is more than that of the original machine, the EATC1 must be high with higher values of $P$.

With the increasing demand rate $(R)$, both $Q$ and EATC1 increase. When the demand rate increases, the manufacturer has to produce more quantity to fulfill the demand. Also, ITO1 and ITB1 increase with the higher demand rate (see Fig. 12c).

When set-up cost $(k)$ increases, the EATC1, $Q$, ITO1, and ITB1 increase (Fig. 12d). The enormous set-up cost generally reduces the number of cycles. As a result, a bigger lot is desirable in this situation.

From Figure 12e, we observe that EATC1 increases while $Q$ decreases enormously with higher values of holding cost $(h)$, i.e., when holding cost increases, the items which are going to be held, must order smaller in size. Also, it is observable from the figure that both ITO1 and ITB1 decrease when $h$ increases.

From Figure 12f, it can be observed that both EATC1 and $Q$ increase as $C_{1}$ increases. But the variation is much more for EATC1. Also, ITO1 increases at a faster rate than ITB1 with higher values of $C_{1}$. It should be noted that for any particular lot, ITO1 is much more than ITB1. As a consequence of this, EATC1 increases widely when $C_{1}$ increases.

With the increase of $C_{2}$, EATC1 increases while $Q$ decreases and both ITB1 and ITO1 decreases slightly (Fig. 12g). The smaller lot size is preferable when $C_{2}$ increases. As if $Q$ is small, then $t_{\mathrm{p}}$ reduces for a fixed value of $P$. Ultimately, usage of buffer machine will be lessened. 


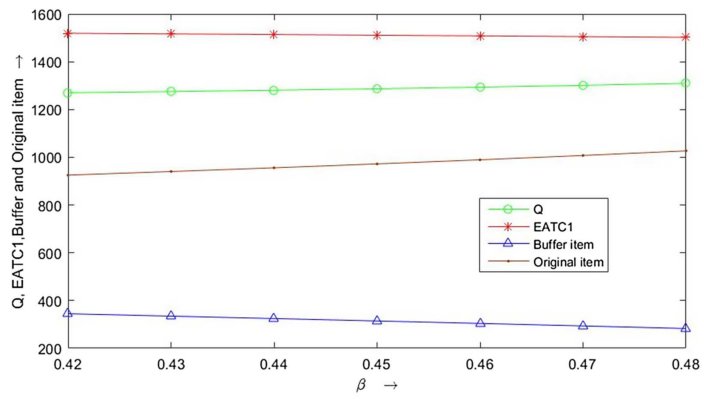

(a)

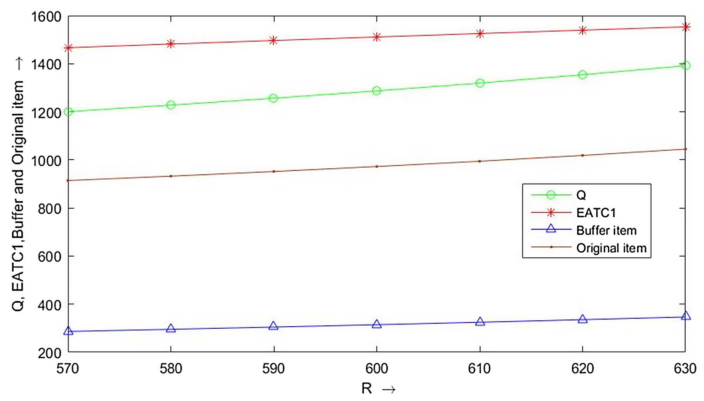

(c)

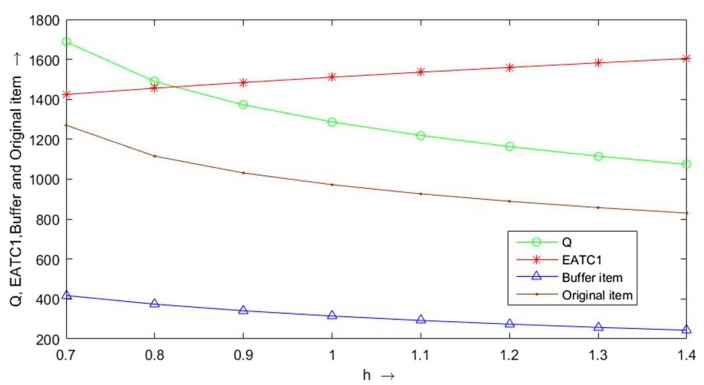

(e)

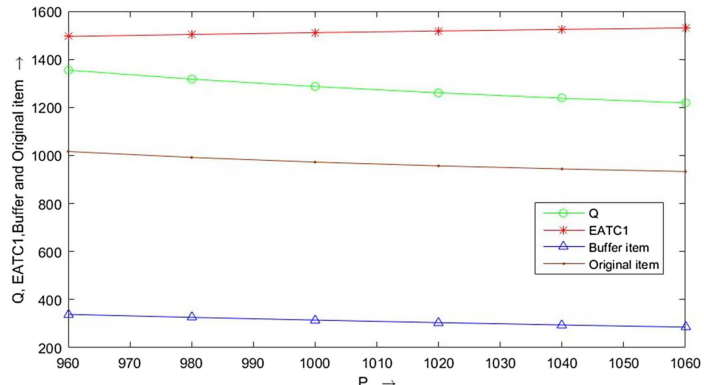

(b)

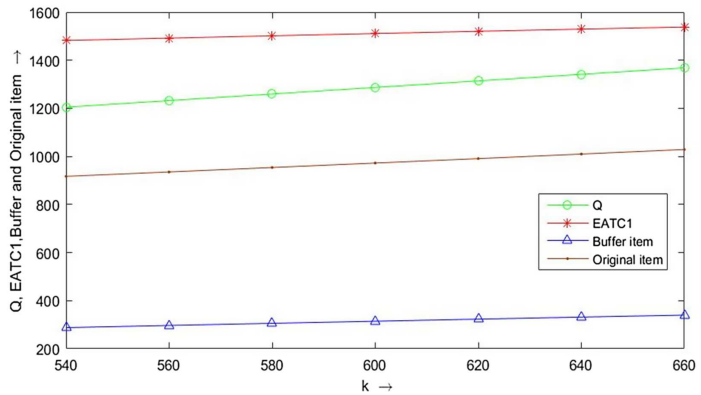

(d)

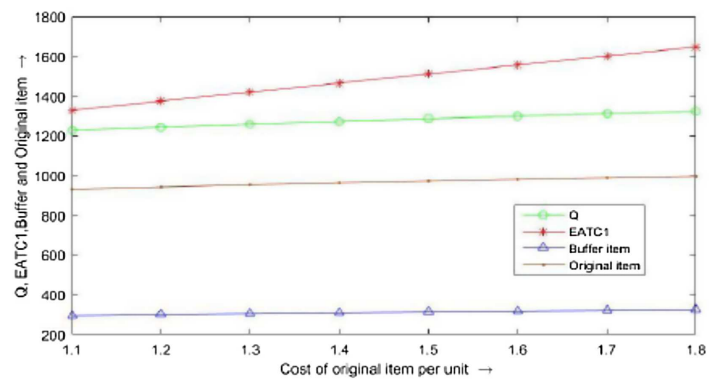

(f)

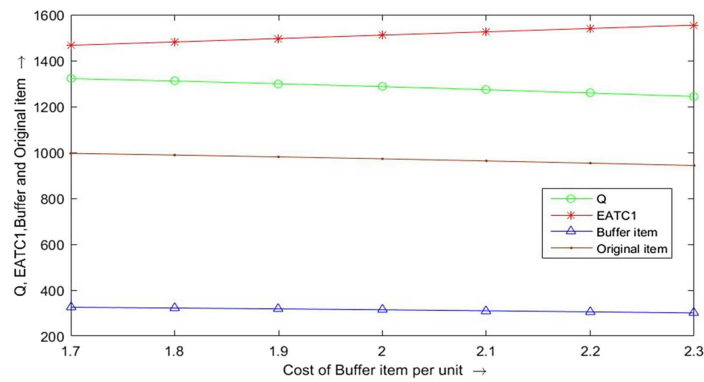

(g)

Figure 12. (a) $Q$, EATC1, buffer and original item versus $\beta$. (b) $Q$, EATC1, buffer and original item versus production rate. (c) $Q$, EATC1, buffer and original item versus demand rate. (d) $Q$, EATC1, buffer and original item versus setup cost. (e) $Q$, EATC1, buffer and original item versus holding cost. (f) $Q$, EATC1, buffer and original item versus cost of original item. (g) $Q$, EATC1, buffer and original item versus cost of buffer item. 


\section{MANAGERIAL INSIGHTS}

From the sensitivity analysis, the manager of a company may get some idea of his future strategy by which he can reduce the average total cost of his organization and improve his business.

\section{Insight 1}

As cost reduction/minimization is the perspective of this model, one manager should try to reduce several cost components like setup cost, holding cost, the production cost of the items produced by the original and buffer machine to minimize the expected average total cost of the system.

\section{Insight 2}

Another decisive question: What will be the size of the ordering lot? There are two options: either he should opt for the smaller or larger lot size. He should prefer a bigger lot when setup cost, demand rate, and cost of items produced by the original machine is emerging. The manager should go for a smaller lot for higher holding costs, production rate, and production cost of the item produced by the buffer machine.

\section{Conclusions}

Here we presented a single-stage production-inventory model where two machines, namely original and buffered, are involved in the manufacturing process. The original machine obeys the principle of the Safe Period. After spending the Safe Period, the original machine faces the problem of random breakdown, and that time, the buffer machine works throughout the repairing period. Analyzing all possible ranges of the Safe Period, we derive the different cost functions, and then we study the analytical, as well as numerical discussion for finding the optional decisions. Numerical examples are exhibited and compared, considering all different cases.

The main improvement of this model is to study the inclusion of two systems properly in a disrupted environment. The main finding of this model is to study two machines in a disrupted environment. We have discussed different cases considering variable ranges of Safe Period as it may fall anywhere on the time horizon in the inventory cycle. The cost of production of a unit of buffering machine is more than that of the original one. As a result, the expected average charge for the buffer system also increases. But from the numerical study, one significant thing can be observed that the increase rate in the average expenditure is not the same proportion with its increment in the use of the buffer machine. We also note that a smaller lot is preferable whenever the working span of the buffer machine increases. Buffer machines can work as a good substitute for the original machine during the latter's corrective maintenance, which is also random here. Consequently, the introduction of the buffer machine is an option for the manufacturer to overcome the stock-out situation. Ultimately, this saves the good-will of a business, which is very important in a competitive market situation in the present scenario.

We can extend the model in many ways. One may consider the unreliable production system and incorporate the reworking of defective items with this model. We may study this model, imposing the effect of deterioration. Another development of this model can be made by taking the price-sensitive demand pattern.

Acknowledgements. The authors would like to express their gratitude to the editors and referees for their valuable suggestions and corrections to enhance the clarity of the present article.

\section{REFERENCES}

[1] N. Bahria, A. Chelbi, H. Bouchriha and I.H. Dridi, Integrated production, statistical process control and maintenance policy for unreliable manufacturing system. Int. J. Prod. Res. 57 (2018) 2548-2570.

[2] V. Boschian, N. Rezg and A. Chelbi, Contribution of simulation to the optimization of maintenance strategies for a randomly falling production system. Eur. J. Oper. Res. 197 (2009) 1142-1149.

[3] T. Chakraborty, B.C. Giri and K.S. Chaudhuri, Production lot sizing with process deterioration under inspection schedule. Omega 37 (2009) 257-271. 
[4] A. Chelbi and D. Ait-Kadi, Analysis of a production/inventory system with randomly failing production unit submitted to regular preventive maintenance. Eur. J. Oper. Res. 156 (2004) 712-718.

[5] G.Q. Cheng, B.H. Zhou and L. Li, Joint optimization of production rate and preventive maintenance in machine systems. Int. J. Prod. Res. 54 (2016) 6378-6394.

[6] S.-W. Chiu, Robust planning in optimization for production system subject to random machine breakdown and failure in rework. Comput. Oper. Res. 37 (2010) 899-908.

[7] S.-W. Chiu, S.-W. Chen, Y.-S.-P. Chiu and T.-W. Li, Production-retailer integrated EMQ system with machine breakdown, rework failures and a discontinuous issuing policy. Springerplus 5 (2016) 339.

[8] M.A. Darwish and M. Ben-Daya, Effect of inspection errors and preventive maintenance on a two-stage production system. Int. J. Prod. Econ. 107 (2007) 301-313.

[9] M.C. Fitouhi and M. Nourelfath, Integrating noncyclical preventive maintenance scheduling and production planning for a single machine. Int. J. Prod. Econ. 136 (2012) 344-351.

[10] B.C. Giri and T. Dohi, Optimal design of unreliable production-inventory systems with variable production rate. Eur. J. Oper. Res. 162 (2005) 372-386.

[11] A.V. Horenbeek, J.B.D. Cattrysse, L. Pintelon and P. Vansteenwegen, Joint maintenance and inventory optimization system: a review. Int. J. Prod. Econ. 143 (2013) 499-508.

[12] C.C. Karamatsoukis and E.G. Kyriakidis, Optimal maintenance of two stochastically deteriorating machines with an intermediate buffer. Eur. J. Oper. Res. 207 (2010) 297-308.

[13] J.P. Kenne, A. Gharbi and M. Beit, Age-dependent production planning and maintenance strategies in unreliable manufacturing system with lost sale. Eur. J. Oper. Res. 178 (2007) 408-420.

[14] T. Kim and C.H. Glock, Production planning for a two-stage production system with multiple parallel machines and variable production rates. Int. J. Prod. Econ. 196 (2018) 284-292.

[15] H.-T. Luong and R. Karim, An integrated production inventory model of deteriorating items subject to random machine breakdown with stochastic repair time. Int. J. Ind. Eng. Comput. 8 (2017) 217-236.

[16] M. Nourelfath, Service level robustness in stochastic production planning under random machine breakdowns. Eur. J. Oper. Res. 212 (2011) 81-88.

[17] B. Pal, S.S. Sana and K.S. Chaudhuri, A multi-echelon production-inventory system with supply disruption. J. Manuf. Syst. 33 (2014) 262-276.

[18] M. Peymankar, F. Dehghanian, Y. Ghiami and H. Abolbashari, The effects of contractual agreements on the economic production quantity model with machine breakdown. Int. J. Prod. Econ. 201 (2018) 203-215.

[19] H. Rafiei, M. Rabbani, H. Vafa-Arani and G. Bodaghi, Production inventory analysis of single-station parallel machine maketo-stock/make-to-order system with random demands and lead times. Int. J. Manage. Sci. and Eng. Manage. 12 (2017), 33-44.

[20] S.S. Sana, Preventive maintenance and optimal buffer inventory for products sold with warranty in an imperfect production system. Int. J. Prod. Res. 50 (2012) 6763-6774.

[21] X. Shi, H. Shen, T. Wu and T.C.E. Cheng, Production planning and pricing policy in amake-to-stock system with uncertain demand subject to machine breakdown. Eur. J. Oper. Res. 238 (2014) 122-129.

[22] A.A. Taleizadeh, L.E. Cardenas-Barron and B. Mohammadi, A deterministic multi product single machine EPQ model with backordering, scraped products, rework and interruption in manufacturing process. Int. J. Prod. Econ. 150 (2014) 9-27.

[23] A.A. Taleizadeh, H. Samimi, B. Sarkar and B. Mohammadi, Stochastic machine breakdown and discrete delivery in an imperfect inventory production system. J. Ind. Manage. Optim. 13 (2017) 1511-1535.

[24] H.M. Wee and G.A. Widyadana, Single vendor single buyer inventory model with discrete delivery order, random machine availability time and lost sales. Int. J. Prod. Econ. 143 (2013) 574-579. 